\title{
A STUDY OF SEGMENTAL BRANCHING PATTERN OF DOUBLE RENAL ARTERIES
}

\author{
Swapna Thampi ${ }^{1}$, Renuka Krishnapillai ${ }^{2}$
}

${ }^{1}$ Assistant Professor, Department of Anatomy, Government Medical College, Thiruvananthapuram.

2 Professor and HOD, Department of Anatomy, Government Medical College, Thiruvananthapuram.

\section{ABSTRACT}

\section{BACKGROUND}

Kidneys can be supplied by multiple renal arteries, which enter at various hilar levels to divide into segmental branches. This study aims to determine segmental contribution by each renal artery to the kidney and also to provide embryologic and clinical correlation.

\section{MATERIALS AND METHODS}

48 formalin fixed cadavers from the Department of Anatomy, Medical College, Kottayam were explored and the variations were studied.

\section{RESULTS}

Double renal artery originating from the aorta was seen in $14.8 \%$. Varied segmental pattern was obtained. Other anomalies also coexisted.

\section{CONCLUSION}

Awareness of variations in existence and branching of multiple renal arteries is of paramount importance for various surgical, urological and angiographic interventions.

\section{KEYWORDS}

Double Renal Artery, Double Renal Vein, Segmental Branches.

HOW TO CITE THIS ARTICLE: Thampi S, Krishnapillai R. A study of segmental branching pattern of double renal arteries. J. Evolution Med. Dent. Sci. 2017;6(22):1784-1787, DOI: 10.14260/Jemds/2017/392

\section{BACKGROUND}

Renal arteries branch laterally from the aorta just below the origin of superior mesenteric artery. The right renal artery is longer and higher passing posterior to Inferior Vena Cava (IVC). It may be crossed anteriorly by inferior mesenteric vein. A single renal artery to each kidney is present in $70 \%$ individuals. Artery varies in their level of origin and their calibre. Near the hilum, each artery divides into anterior and posterior division, which in turn divides into segmental arteries supplying renal vascular segments. Multiple renal arteries are common in 30\% individuals. An artery arising from aorta in addition to main renal artery is called accessory artery. Arteries arising from other sources like celiac trunk, superior mesenteric artery or common iliac arteries are called aberrant renal arteries. Such aberrant renal arteries have been described by Ionescu et al (1962) and Orlandini (1966). It has been observed from various studies that accessory renal arteries are actually normal segmental arteries with precocious origin. Hence, they are not additional vessels. Knowledge of renal vascular anomalies are important in renal transplantation, urologic procedures, segmental resections, etc. This study aims to find varying relations of multiple renal arteries, other branches arising from them and their segmental distribution.

Financial or Other, Competing Interest: None.

Submission 28-01-2017, Peer Review 04-03-2017,

Acceptance 10-03-2017, Published 16-03-2017.

Corresponding Author:

Dr. Renuka Krishnapillai,

Rasmi, TC-41/1689, Manacaud,

Thiruvananthapuram - 695009.

E-mail:drrenukak@rediffmail.com

DOI: $10.14260 /$ jemds $/ 2017 / 392$

\section{MATERIALS AND METHODS}

The formalin fixed 48 cadavers from the Department of Anatomy, Government Medical College, Kottayam were studied. Along with routine dissection for undergraduates, after opening the abdomen other viscera were removed and relations of hilar structures were noted. Twelve kidneys were found to have double renal arteries, all arising from the aorta. Level of origin was noted and each vessel was traced to the kidneys. Relations with IVC, ureter and gonadal vessels was specifically looked for. Then kidneys were removed after dividing ureter and vessels. Each renal artery was traced dissecting the kidney and its branching pattern was studied.

\section{RESULTS}

We observed double renal arteries in $14.8 \%$ (12 kidneys) cases. Both the arteries originated from the aorta and had different levels of origin (Table 1).

In 8 kidneys (75\%), both renal artery entered through the hilum, one usually in normal position. Rest of them showed the following variations -

a. One kidney had persistent foetal lobulations and double renal arteries represented anterior and posterior division arising from the aorta separately (Fig. 1 and 2).

b. In one kidney (right) the upper renal artery (L1 level) passed posterior to IVC to enter through upper part of hilum, while the lower renal artery (L3 level) crossed anterior to IVC, right pelvi-uretric junction and entered through lower part of hilum. It also gave testicular artery while crossing IVC and was crossed anteriorly by testicular vein (Fig. 3). Other coexisting anomaly crossed the double renal vein.

c. In one kidney (right) one renal artery had hilar entry after giving testicular branch, while the other was superior polar artery arising in common with inferior phrenic 
artery just lateral to origin of coeliac trunk. It gave adrenal branch and entered through cortex (Fig. 4).

d. In one case (right side) upper renal artery (L1 level) descended crossing in front of lower renal artery (L2 level) to enter through the lower part of hilum and supplied to lower segment. The lower renal artery passed straight into hilum and supplied rest of the segments.

After entering the kidney, each renal artery divided into segmental branches. Segmental distribution of each renal artery was observed and classified as upper, middle, lower and posterior segmental arteries (Table 2). In this study in $58.33 \%$ cases one of the renal artery supplied the lower segment, where the other supplied the upper, middle and posterior segments (Fig. 5), Table 2.

\begin{tabular}{|c|c|}
\hline Vertebral Levels of Origin & Percentage of Kidneys \\
\hline L1 and L3 & $66.67 \%$ (8 kidneys) \\
\hline L1 and L2 & $16.67 \%$ (2 kidneys) \\
\hline Both at L1 & $16.67 \%$ (2 kidneys) \\
\hline Table 1. The Different Levels of Origin of Renal Arteries \\
\hline
\end{tabular}

\begin{tabular}{|c|c|}
\hline $\begin{array}{c}\text { The two arteries represent anterior and } \\
\text { posterior divisions respectively. }\end{array}$ & $\begin{array}{c}16.67 \% \\
(2 \text { kidneys })\end{array}$ \\
\hline $\begin{array}{c}\text { One artery is lower segmental artery while other } \\
\text { gives all other segmental branches. }\end{array}$ & $\begin{array}{c}58.33 \%(7 \\
\text { kidneys })\end{array}$ \\
\hline $\begin{array}{c}\text { One artery divides into lower and middle } \\
\text { segmental artery, while other gives upper } \\
\text { posterior segmental artery. }\end{array}$ & $\begin{array}{c}16.67 \% \\
(2 \text { kidneys })\end{array}$ \\
\hline $\begin{array}{c}\text { One artery divides as normal. The other is upper } \\
\text { polar artery. }\end{array}$ & $\begin{array}{c}8.33 \% \\
(1 \mathrm{kidney})\end{array}$ \\
\hline \multicolumn{2}{|c|}{ Table 2. Segmental Branches of Each Renal Artery } \\
\hline
\end{tabular}

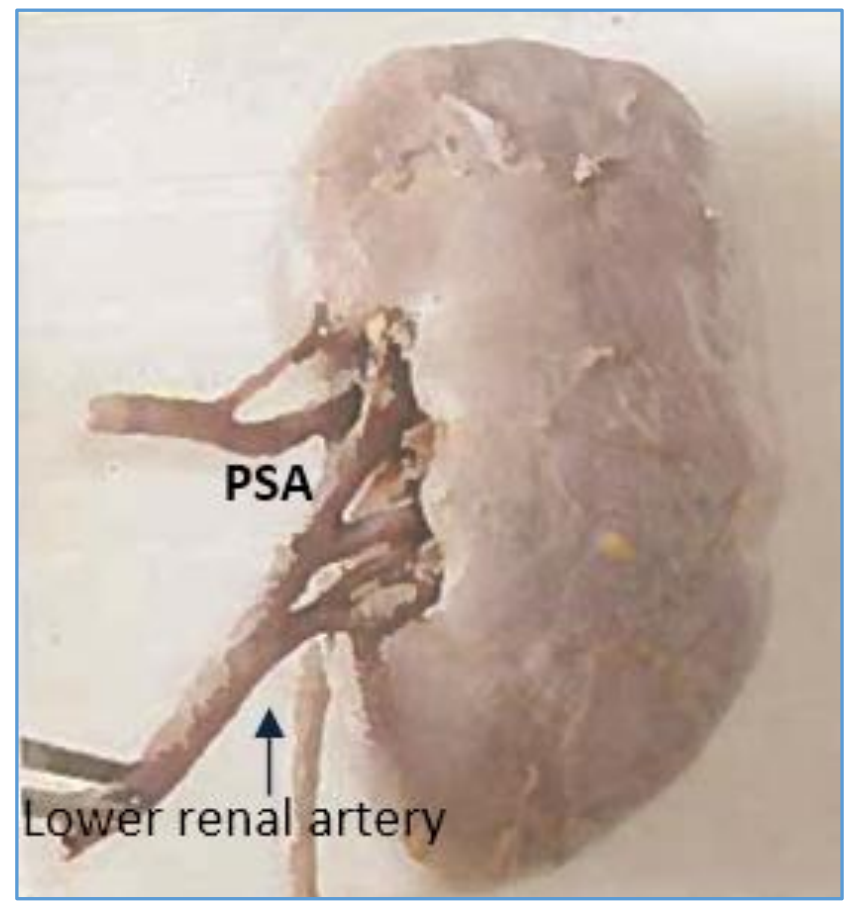

Figure 1. Left Kidney with Two Arteries. Upper one gives PSA (Posterior Segmental Artery), while Lower one gives rest of the Segmental Branches

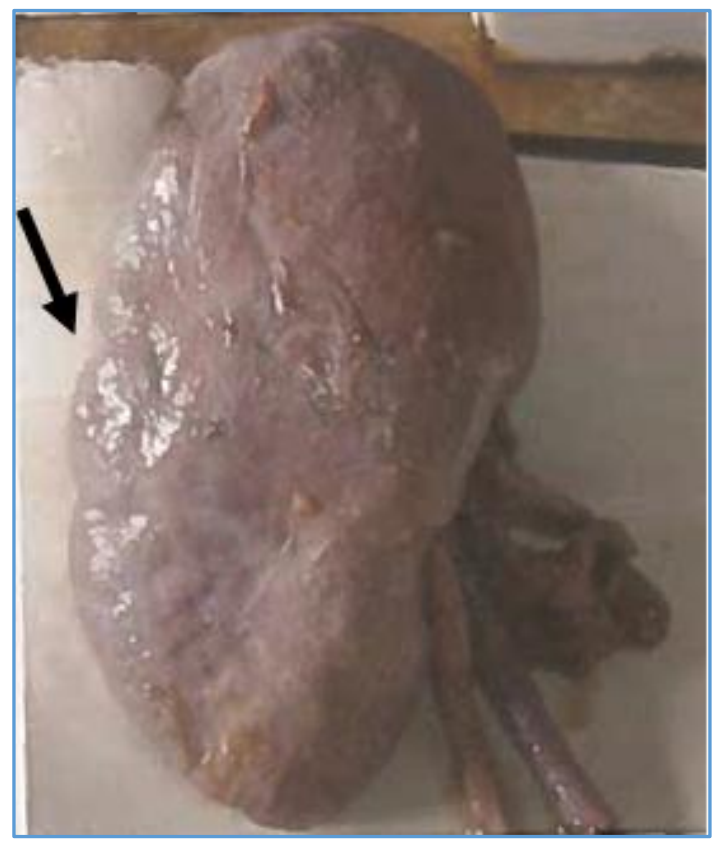

Figure 2. Posterior View of same Kidney showing Foetal Lobulations (Arrow)

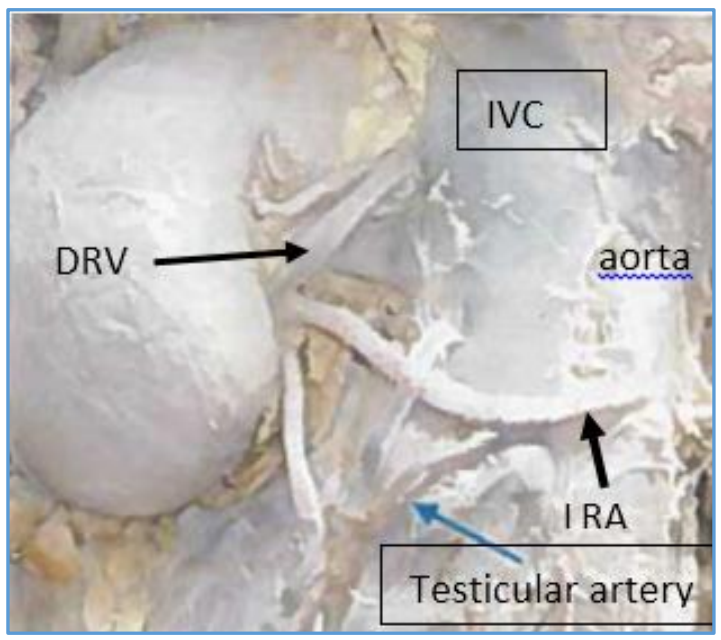

Figure 3. LRA (Lower Renal Artery) passing Precavally, giving Testicular Artery. DRV (Double Renal Vein) also Seen

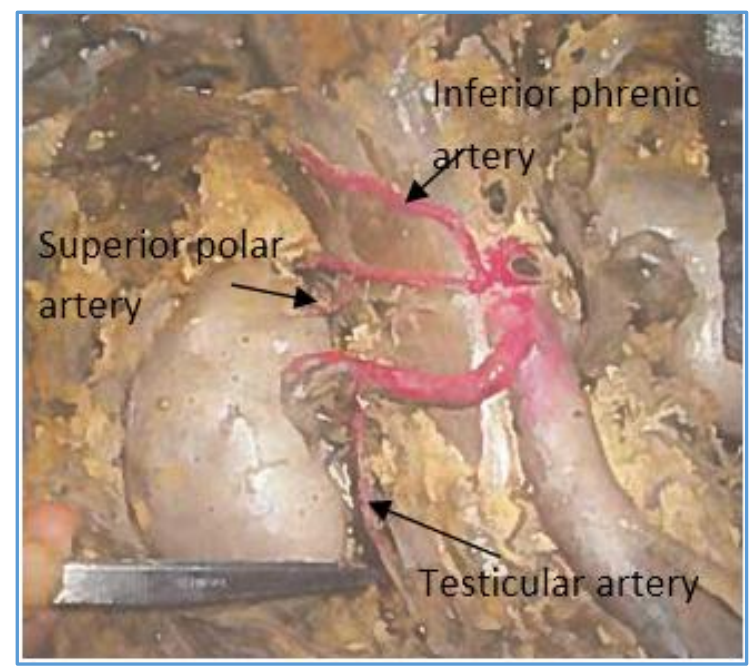

Figure 4. Right Kidney showing Superior Polar Artery arising in common with Inferior Phrenic Artery. Main Renal Artery also gives Testicular Artery 


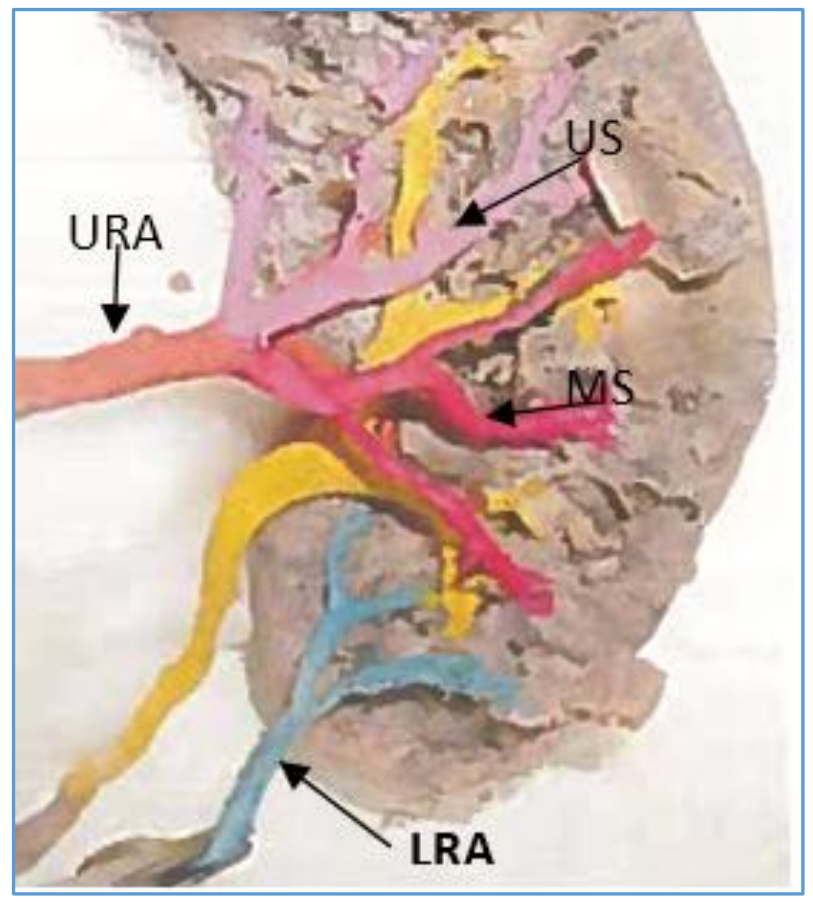

Figure 5. URA (Upper Renal Artery) gives US (Upper Segmental), MS (Middle Segmental) and PS (Posterior Segmental) Arteries. LRA (Lower Renal Artery) supplies Lower Segment

\section{DISCUSSION}

Renal vascular segmentation was originally recognised by John Hunter in 1794 and first given by Graves. ${ }^{1}$ The arterial pattern was reviewed by Fourman ${ }^{2}$ and Moffat in 1971 and was applied to segmental resection of kidneys.

George Gerard, ${ }^{3} 1911$ in his study of 150 pair of kidneys was first to recognise the extra renal arteries, which was due to an early division of the main renal artery rather than true multiplication or increase in number of arteries. The various types of accessory artery, their position, method of entry into the kidney and its segmentation was extensively studied by Skyes ${ }^{4}$ in 1963 . Rossi et al ${ }^{5}$ reported a case with 7 renal arteries. FJB Sampio and Passo ${ }^{6}$ in 1992 dissected 266 kidneys and found multiple renal arteries in $46.7 \%$. In this study, double renal artery was observed in $14.8 \%$. Sampaio and Favorito 7 1993; Rouviere et al 1999 reported incidence of anomalous renal vessels crossing the renal pelvis to be $29 \%$ to $65 \%$. In this study, the incidence was $16.67 \%$. K S Satyapal ${ }^{9}$ et al, 2001 found that out of 130 angiograms and 32 cadavers, $23.2 \%$ kidneys showed the presence of 2 renal arteries and $4.5 \%$ showed 3 renal arteries. Bordei ${ }^{10}$ et al in 2004 reported 54 cases of double renal arteries supplying one kidney originating from the aorta. They also showed these may coexist with other urovascular variations such as double renal veins, double ureter, persistence of foetal lobulations and genital arteries originating from accessory renal arteries. Present study also showed similar results. Lower polar artery, which pass in front of ureter are associated with relatively higher incidence of hydronephrosis (Anson BJ ${ }^{11}$ et al, 1936). Such vessels are likely to be injured during nephrolithotomies.

Embryonic mesonephros is supplied by about 30 lateral branches, which develop as segmental arteries from dorsal aorta extending from C6 to L3 segment forming a network called rete arteriosum urogenitale. The gonad, adrenal and ureter obtain their blood supply from this source (Felix, 1912). ${ }^{12}$ As the mesonephros differentiates into a kidney, it successively acquires the segmental arteries that connect rete to the aorta. As the kidney ascends, the arterial degeneration begins at the cephalad end of the metanephros, the segmental branch to the lower pole is the one most likely to persist as an accessory vessel (Graves 1969). A persistent segmental artery to lower pole may provide the origin of the gonadal artery and the one to the upper pole may give an adrenal artery (Bremer, 1915).13 Ravery ${ }^{14}$ et al explained origin of testicular artery from accessory renal arteries, as both have a common source of origin and testis receives branches during anterior crossing of kidneys. Prior knowledge helps the surgeons to prevent iatrogenic testicular atrophy. Also other post-operative complications are epididymitis, testicular swelling and infarction, renal artery stenosis, etc. Studies have shown when the diameter of main renal artery is less than $4.15 \mathrm{~mm}$, the presence of additional renal artery is probable. ${ }^{15}$ These arteries tend to be longer and narrower resulting in low perfusion pressure. They are associated with hypertension in young patients. ${ }^{16}$ Frequency of accessory renal artery to lower pole was found to be more by some workers. Present study results are also consistent with it. Awareness of the presence of precaval accessory renal artery is important to prevent massive bleeding during surgeries with retroperitoneal approach. ${ }^{17}$ Earlier donors with multiple renal arteries were rejected, but now with high demand for transplants it is considered as a challenge during donor nephrectomy. Increased complications have been reported by Simmons ${ }^{18}$ et al 1971, which include risk of rejection, acute tubular necrosis, post-transplant hypertension and late vascular and urologic complications. So prior multi-detector CT angiography and arteriography has to be done before renal transplantation, endovascular repair of aneurysms and renal artery stenosis correction in order to diagnose accessory vessels. This study may be useful for surgeons, interventional radiologists, nephrologists and vascular surgeons.

\section{CONCLUSION}

In this study $14.8 \%$ cases showed double renal arteries, both of aortic origin. Coexisting anomalies were presence of foetal lobulations, double renal vein, origin of testicular artery from renal artery and precaval renal artery. The double renal arteries had different segmental distributions. Knowledge of renal arterial pattern and its variations is important to prevent pre- and post-operative complications. Hence, preoperative imaging is essential before transplantation, vascular reconstructions, endourologic procedures and retroperitoneal surgeries. Present study will help to enhance knowledge of segmental branching pattern of double renal arteries.

\section{REFERENCES}

[1] Graves FT. The arterial anatomy of the congenitally abnormal kidney. Br J Surg 1969;56(7):533-41.

[2] Fourman J, Moffat DB. The blood vessels of the kidney. Oxford: Blackwell, 1971.

[3] Gerard G. Les arteres $r \sim$ nales (note statistique d'apres l'6tude de 150 paires de reins). J Anat Physiol Paris 1911;47:531-4. 


\section{Jemds.com}

[4] Sykes D. The arterial supply of human kidney with special reference to accessory arteries. British Journal of Surgery 1963;50(222):368-74.

[5] Rossi UG, Romano M, Ferro C. Seven renal arteries. Clin Anat 2006;19(7):632-3.

[6] Sampaio FJ, Passos MA. Renal arteries: anatomic study for surgical and radiological practice. Surg Radiol Anat 1992;14(2):113-7.

[7] Sampaio FJ, Favorito LA, Schiavini JL. Proportional analysis of the kidney arterial segments. Urol Res 1993;21(6):371-4.

[8] Rouvière 0 , Lyonnet $D$, Berger $P$, et al. Ureteropelvic junction obstruction: use of helical CT for preoperative assessment: comparison with intraarterial angiography. Radiology 1999;213(3):668-73.

[9] Satyapal KS, Haffejee AA, Singh B, et al. Additional renal arteries: incidence and morphometry. Surg Radiol Anat 2001;23(1):33-8.

[10] Bordei P, Sapte E, Iliescu D. Double renal arteries originating from the aorta. Surg Radiol Anat 2004;26(6):474-9.

[11] Anson BJ, Richardson GA, Minear WL. Variations in the number and arrangement of the renal blood vessels, a study of the blood supply of four hundred kidneys. J Urol 1936;36:211-9.

\section{Original Research Article}

[12] Fellix W. Mesonephric arteries. In: Kiebel F, Mall FP, (eds). Manual of human embryology. Vol 2. Philadelphia: Lippincott, 1912:820-5.

[13] Bremer JL. The origin of the renal artery in mammals and its anomalies. Developmental Dynamics 1915;18(2):179-200.

[14] Ravery V, Cussenot O, Desgrandchamps F, et al. Variations in arterial blood supply and the risk of hemorrhage during percutaneous treatment of lesions of the pelviureteral junction obstruction: report of a case of testicular artery arising from an inferior polar renal artery. Surg Radiol Anat 1993;15(4):355-9.

[15] Saldarriaga B, Pinto SA, Ballesteros LE. Morphological expression of the renal artery. A direct anatomical study in a Colombian half-caste population. Int J Morphol 2008;26(1):31-8.

[16] Mehta G, Arole V. Arterial segmentation of human kidneys. IJCRR 2014;6(11):58-62.

[17] Yeh BM, Coakley FV, Meng MV, et al. Precaval right renal arteries, prevalence and morphologic associations at spiral CT. Radiology 2004;230(2):42933.

[18] Simmons RL, Najarian JS. Kidney transplantation. In: Simmons RL, Finck ME, Ascher NL, et al. (eds). Manual of vascular access, organ donation, and transplantation. New York: Springer-Verlag, 1984:292-328. 